\title{
1.15
}

\section{Direito Ambiental do Trabalho e a saúde dos trabalhadores da pesca artesanal: estudo de caso}

Environmental Law and health of workers of artisanal fishery: a case study

\section{Ingrid Gil Sales Carvalho}

Advogada, Mestra em Saúde, Ambiente e Trabalho. Universidade Federal da Bahia (UFBA). Salvador, Brasil.

\section{Rita de Cássia Franco Rêgo}

Médica, Doutora em Saúde Pública. Universidade Federal da Bahia (UFBA). Salvador, Brasil.

Resumo: O presente tem objetiva refletir sobre o Direito Ambiental do Trabalho (DAT) na perspectiva contributiva da saúde do trabalhador da pesca artesanal. Trata-se de pesquisa bibliográfica/documental em que foram consultados documentos originais, livros, artigos, leis, projetos, regulamentos, pareceres e relatórios, utilizando-se das seguintes palavras-chave: ambiente, meio ambiente, trabalho, saúde, saudável, direito ambiental, direito do trabalho, direito ambiental do trabalho, pesca, pescador, artesão, artesanal. O Direito do Trabalho (DT) se constitui de normas específicas vinculadas à promoção da saúde e da segurança para o trabalhador e, assim como o Direito Ambiental (DA), que cuida da normatização, tanto no ambiente natural, quanto do artificial, são dois ramos do Direito Brasileiro que se sobressaem na amplitude e eficácia das normas de proteção à saúde do trabalhador. O meio ambiente de trabalho está centralizado na pessoa do trabalhador e no desenvolvimento de sua atividade laboral. $O$ meio ambiente de trabalho é o local onde as pessoas desempenham suas atividades laborais. No caso do pescador artesanal, este se encontra imerso ao mesmo tempo no seu ambiente natural e artificial. Assim, qualquer contaminação, poluição ou dano ao meio ambiente natural afeta diretamente o pescador artesanal e, por conseguinte, a sua saúde. Evidenciou-se uma escassez na produção científica do Brasil, que aborde diálogos entre a saúde do pescador artesanal e o seu direito a um meio ambiente de trabalho saudável. Acredita-se que o DAT pode contribuir positivamente para a regulamentação da garantia do Direito à Saúde do pescador artesanal no Brasil no seu meio ambiente de trabalho.

Palavras-chaves: Direito do Trabalho; Direito Ambiental; Direito Ambiental do Trabalho; Pesca artesanal.

Key-words: Labor Law; Environmental Law; Environmental Labor Law; Artisanal Fishery. 
Ao se abordar a temática do Direito Ambiental do Trabalho parcos são os autores brasileiros que tratam do mesmo. Distinguem-se pelo modo como examinam a matéria, autores como: Rocha (1996, 1997, 2002), Pinto (1997), Sady (2000), Figueiredo (2000, 2007), Padilha (2002), Soares (2004), Melo (2010) e Santos (2010). É justamente no Direito Ambiental do Trabalho que encontramos princípios, definições e um arcabouço jurídico, ambos precisos na defesa da tutela do meio ambiente de trabalho saudável, equilibrado e seguro.

Para tratar do Direito Ambiental do Trabalho na defesa do meio ambiente de trabalho saudável de pescadores artesanais faz-se necessário primordialmente compreender como se origina essa estrutura disciplinar jurídica específica, retomando a criação do Direito do Trabalho e o objeto tutelado pelo mesmo, bem como o surgimento do Direito Ambiental e o objeto tutelado por esse. Isso, Trabalho e Ambiental, enquanto disciplinas autônomas do Direito que contribuíram decisivamente na formação de uma nova disciplina jurídica, o Direito Ambiental do Trabalho, cuja principal preocupação é a defesa do meio ambiente de trabalho.

O objetivo do presente artigo é fazer uso dos instrumentos do Direito Ambiental do Trabalho na defesa do meio ambiente de trabalho saudável dos pescadores artesanais, para tanto se buscou estabelecer as bases científicas do Direito Ambiental do Trabalho, bem como a definição da pesca artesanal, da atribuição do pescador artesanal e do meio ambiente de trabalho desse, enquanto categoria diferenciada por conjugar o seu meio ambiente natural ao seu meio ambiente de trabalho.

De forma uníssona, parece-nos que os autores (Melo, 2010; Figueiredo, 2007; Soares, 2004; Rocha, 2002; Sady, 2000) que tratam da temática da origem do Direito Ambiental do Trabalho no Brasil como uma disciplina jurídica autônoma apontam a Revolução Industrial como um fator histórico preponderante no surgimento e consagração das normas do Direito do Trabalho, bem como das normas do Direito Ambiental.

Guilherme José Purvin de Figueiredo (2007, p. 23) é categórico ao afirmar que para ele o Direito do Trabalho nasce de um quadro histórico bastante definido: o advento da Revolução Industrial. Para o autor (2007, p. 23), o tema recorrente no Direito do Trabalho "é a questão social, e a sua finalidade, claramente tutelar, é de promover a dignidade dos seres humanos ou, mais especificamente, daqueles que trabalhavam nas indústrias". 
Julio Cesar de Sá da Rocha (2002, p. 49) não pensa diferente, para ele o Direito do Trabalho tem origem nas circunstâncias econômicas e sociais determinadas, precipuamente, pela Revolução Industrial e pelo surgimento da classe operária. Segundo Rocha (2002, p. 49):

a noção do direito do trabalho somente pode ser apreendida diante dessa perspectiva histórica, sobretudo diante do conjunto de acontecimentos que se vieram elaborando: consciência dos trabalhadores, intervenção estatal e proteção legal.

Por certo, a Revolução Industrial, além de trazer consigo o surgimento do proletariado, trouxe também um processo intensivo de degradação do meio ambiente e das condições de salubridade do ser humano, sujeitando-o a doenças e acidentes decorrentes do trabalho. Figueiredo (2007, p. 23) relata que com a Revolução Industrial "a produção em série impõe maior demanda de matéria-prima vinda do campo e na cidade, maior concentração populacional e especialização no trabalho".

Nesse sentido, Rocha (2002) e Evanna Soares (2004) entendem que o Direito do Trabalho é justamente o resultado da crise do modelo econômico liberal, somada a necessidade da emergência da intervenção estatal e acrescida da consciência da classe trabalhadora a respeito das condições de vida no trabalho.

Dessa forma, o Direito do Trabalhador, como bem expõe Figueiredo (2007), Rocha (2002) e Soares (2004), nasceu com a finalidade precípua de promover a proteção da vida e da saúde dos trabalhadores, por meio de normas que buscavam alcançar as condições de trabalho e até mesmo o meio ambiente em que esse trabalho era desenvolvido. Para Figueiredo (2007, p. 23) o Direito do Trabalho foi, em sua origem, um ramo do direito diretamente vinculado à proteção da saúde e de um meio ambiente sadio.

Rocha (2002, p. 61) denomina de a "constitucionalização dos direitos sociais", o período relativo ao início do século $X X$, quando as normas de proteção ao trabalhador são incorporadas à Constituição. De acordo com Paulo Mazzante de Paula (2012, p. 45), a primeira Constituição Federal no mundo que fez previsão do trabalho como um direito social foi a Constituição Mexicana de 1917 e, a segunda, considerada a base da democracia social, foi a Constituição de Weimar, na Alemanha, no ano de 1919.

Tais Constituições se tornaram um marco político de estabelecimento de garantias mínimas e essenciais ao trabalhador para, segundo Rocha (2002, p. 62), "protegê-lo contra qualquer política do legislador ordinário". Ademais, a incorporação 
dos direitos sociais, dentre eles, o direito ao trabalho digno, suas formas, condições e tratamento nas Constituições representa a elevação do patamar do Direito dos Trabalhadores.

Não obstante, no ano de 1919 é criada a Organização Internacional do Trabalho (OIT) por meio do Tratado de Versalhes, que instituía uma Organização Internacional cujo objetivo era o de proporcionar a justiça social entre os povos, condição de acordo com Paula (2012, p. 45) primordial para a manutenção da paz mundial na época pós Primeira Guerra Mundial.

Para Paula (2012, p. 46) a Organização Internacional do Trabalho desenvolve um importante papel na proteção e preservação da saúde e vida do trabalhador. Citando em sua obra as principais Convenções e Recomendações da OIT como marcos regulatórios internacionais até os dias de hoje, veja-se, pois:

a) Recomendação $n^{\circ} 20$, de 1923: princípios gerais da organização dos serviços de inspeção para garantir a aplicação das leis e regulamentos de proteção aos trabalhadores;

b) Recomendação $n^{\circ}$ 31, de 1929: prevenção dos acidentes do trabalho;

c) Convenção no 115, de 1960, e Recomendação n. 114: proteção contra radiações

d) Convenção $n^{\circ} 120$ e recomendação $n^{\circ} 120$ ambas de 1964: conservação, limpeza, ventilação, iluminação, temperatura, produtos insalubres ou tóxicos, poluição sonora, vibrações etc. em estabelecimentos públicos e privados;

e) Convenção $n^{\circ} 139$ e Recomendação $n^{\circ}$ 147, de 1974: prevenção e controle dos riscos profissionais causados por substâncias ou agentes cancerígenos;

f) Convenção n 167, de 1988: segurança e saúde na construção;

g) Convenção n 176, de 1995: segurança e saúde nas minas.

No Brasil, a primeira Carta Magna a adotar as normas de Direito do Trabalho foi a de 1934, segundo Paula (2012, p. 47), incentivada pela política trabalhista da época que marcou a ditadura populista implantada por Getúlio Vargas em 1930. Para José Fábio Rodrigues Maciel e Renan Aguiar (2007, p. 58), a Constituição Federal de 1934 recebeu ampla influência da Constituição Alemã de Weimar, tratando da ordem social, constitucionalizando as normas do Direito do Trabalho ao legislar sobre a proteção do empregado, prevendo, por exemplo, jornada de oito horas diárias, férias, assistência médica do trabalhador e da gestante. 
Atualmente, de acordo com Celso Antonio Pacheco Fiorillo (2010), a nossa Carta Magna, legisla amplamente sobre o direito ao trabalho (art. 6ํ), o direito as justas e favoráveis condições de trabalho (art. $7^{\circ}$ ), nelas relacionadas as condições de trabalho seguras e saudáveis, o direito à saúde (art. 12), que nele inclui melhorias relacionadas com o meio ambiente.

Para Rocha (2002, p. 72), foi no século XIX, com a Revolução Industrial introduzindo em larga escala a máquina a vapor e em consequência a utilização maciça do carvão que o planeta Terra começou a sentir de modo assustador os efeitos da poluição e da degradação no planeta. Segundo o autor (2002, p. 72), "após essa fase, os impactos começaram a ser sentidos com tamanha intensidade que se fez necessária uma intervenção contra a degradação ambiental".

Nesse sentido, entendem Figueiredo (2007), Rocha (2002) e Sady (2000) que as condições socioambientais e o processo de produção econômica, ocasionados como consequências diretas da Revolução Industrial deram ensejo ao surgimento de uma legislação que hoje é denominada de ambiental. Para Figueiredo (2007, p. 24) é justamente "em virtude da degradação da qualidade de vida, não só do trabalhador, mas também de todo o ambiente exterior, isto é além dos muros das fábricas" que o Direito Ambiental irá se materializar como norma jurídica de cunho internacional.

Segundo Rocha (2002) o Direito Ambiental como uma ciência jurídica autônoma é recente. Figueiredo (2007, p. 24) explicita que, o que hoje denominamos de Direito Ambiental, ramo das ciências jurídicas que se ocupa com a qualidade do meio ambiente, somente se formalizará como tal nas décadas de 1960 e 1970, ao que ele atribui significativamente à Convenção de Estocolmo de 1972.

De acordo com Rocha (2002) a formação do Direito Ambiental, enquanto disciplina autônoma do ramo jurídico que visa à proteção, preservação e segurança do ambiente como um todo, perpassa por momentos históricos distintos que vão além e cuja formação tem o seu nascedouro anterior à Convenção de Estocolmo de 1972 referida por Figueiredo (2007).

Aduz Rocha (2002, p. 72-73) que o Direito Ambiental tem sua formação com os primeiros tratados de proteção de determinados recursos naturais, precisamente no ano de 1867, com a Convenção entre França e Grã-Bretanha, proibindo a pesca de ostras em determinados períodos, o que evidencia para o autor o início da compreensão das consequências e efeitos do processo acelerado da industrialização no meio ambiente. 
Entende Rocha (2002, p. 73) que a Conferência de Estocolmo (1972) torna-se um marco histórico ao permitir a criação e/ou desenvolvimento de organizações internacionais e legislações importantes que tratam de modo específico da matéria ambiental, como por exemplo, a Organização das Nações Unidas para a Alimentação e Agricultura (FAO), a Organização Mundial de Saúde (OMS) e tantos outros referidos pelo autor em sua obra. Rocha (2002, p. 73) cita ainda como marco histórico para o Direito Ambiental a Conferência das Nações Unidas para o Meio Ambiente e Desenvolvimento ocorrida no Rio de Janeiro (1992) que resultou no Programa das Nações Unidas para o Meio Ambiente (PNUMA).

Segundo Melo (2010, p.29) o Direito Ambiental possui como marco histórico no Brasil a edição da Política Nacional do Meio Ambiente, através da Lei nํㅜ 6.938 de 1981, que em seu art. 3ํㅡ, inciso I, legisla especificadamente sobre meio ambiente, expondo: "É conjunto de condições, leis, influências e interações de ordem física, química e biológica, que permite, abriga e rege a vida em todas as suas formas". O conceito amplo de Meio Ambiente, conferido pela Política Nacional do Meio Ambiente, bem como diversas normas do Direito Ambiental receberam tratamento diferenciado na Carta Magna de 1988, ao passarem a integrar o texto da mesma, que em seu art. 225, caput, tutela todos os aspectos do meio ambiente, afirmando que "todos têm direito ao meio ambiente ecologicamente equilibrado, bem de uso comum do povo e essencial a sadia qualidade de vida".

Como bem coloca José Afonso da Silva à respeito da Constituição de 1988 e o Direito Ambiental (2004, p. 46):

a Constituição de 1988 foi, portanto, a primeira a tratar deliberadamente da questão ambiental, trazendo mecanismos para sua proteção e controle, sendo tratada por alguns como "Constituição Verde".

Ora, autores como Hubert Seillan (1994, p. 37) afirmam que o Direito do Trabalho e o Direito Ambiental são resultados do insucesso do princípio liberal do laissé faire, que se desenvolveram e se formaram em épocas e por condições diferentes. Os dois ramos do Direito surgem em virtude das consequências produzidas, respectivamente, na saúde e vida do ser humano e na natureza.

Outrossim, tanto o Direito Ambiental como o Direito do Trabalho, cada um a seu modo, têm legislado sobre o meio ambiente de trabalho. Rocha (2002, p. 274) afirma que cada um desses campos do saber jurídico, de per si não conseguem compreender a dimensão do meio ambiente do trabalho. E por isso, seria necessário 
um campo jurídico específico, com seus princípios norteadores e regras postulares próprias a tratar do meio ambiente de trabalho saudável, seguro e sustentável. Esse campo do Direito se traduz no Direito Ambiental do Trabalho.

Rocha (2002, p. 274) explicita que o não tratamento adequado do meio ambiente de trabalho quer pelo Direito Ambiental, quer pelo Direito do Trabalho se dá em virtude das ciências jurídicas citadas possuírem postulados e princípios que lhe são peculiares. Entendendo ademais, que:

o Direito Ambiental do Trabalho está emergindo como um sistema normativo a legislar sobre o meio ambiente do trabalho como uma racionalidade baseada na prevenção ao dano e na precaução. (Rocha, 2002, p. 274)

Para Figueiredo (2007), Soares (2004) e Rocha (2002), o Direito do Trabalho objetiva a regulação das relações trabalhistas e principalmente a proteção do trabalhador hipossuficiente, enquanto o Direito Ambiental visa a proteção e preservação do meio ambiente, bem como da vida no planeta Terra.

Nesse sentido, quem melhor descreve o conceito de Direito Ambiental do Trabalho, distinguindo do conceito do Direito Ambiental e do Direito do Trabalho é Rocha (2002, p. 274), o qual assim descreve:

é compreendido como sistema normativo que tutela o meio ambiente do trabalho (de forma imediata) e a saúde dos trabalhadores (de forma indireta) e como disciplina jurídica in statu nascendi, que descreve e compreende essa proteção normativa, tendo em vista 0 trabalhador em seu entorno de trabalho.

Para Celso Antonio Pacheco Fiorillo e Marcelo Abelha Rodrigues (1999, p. 35) o objeto precípuo do Direito Ambiental do Trabalho é o meio ambiente do trabalho, e entende-se por meio ambiente de trabalho, de acordo com os autores: "o local onde se exerce qualquer atividade laboral" (Fiorillo; Rodrigues, 1999, p. 35).

Expõe Melo (2010, p. 30-31) de modo apropriado que o conceito de meio ambiente do trabalho é:

- local onde as pessoas desempenham suas atividades laborais, sejam remuneradas ou não, cujo equilíbrio está baseado na salubridade do meio e na ausência de agentes que comprometam a incolumidade físico-psíquica dos trabalhadores, independentemente da condição que ostentem (homem ou mulheres, maiores ou menores de idade, celetistas, servidores públicos, autônomos e etc.).

O referido conceito listado por Melo (2010, p. 30-31) é importante porque traz uma idéia generalista de meio ambiente de trabalho e, portanto, alarga o objeto de estudo do Direito Ambiental do Trabalho. O qual não deve ser entendido como restrito ao estudo das normas de segurança, saúde e de higiene dos trabalhadores da 
indústria ou do comércio, mais também de todos os tipos de trabalhadores, independentemente de serem regidos pela Consolidação das Leis do trabalho (CLT) ou por um estatuto funcional, de possuírem ou não um vínculo formal de relação empregatícia.

Entendemos ainda que a melhor definição de meio ambiente do trabalho é a de Rodolfo de Camargo Mancuso em sua obra (1999, p. 61):

O meio ambiente do trabalho vem a ser o 'habitat laboral', isto é, tudo que envolve e condiciona, direta e indiretamente, o local onde o homem obtém os meios para prover o quanto necessário para sua sobrevivência e desenvolvimento, em equilíbrio com o ecossistema. A contrario sensu, portanto, quando aquele 'habitat' se revele inidôneo a assegurar as condições mínimas para uma razoável qualidade de vida do trabalhador, ai se terá uma lesão ao meio ambiente do trabalho.

Dessa forma, José Afonso da Silva (2000, p. 23), acertadamente aponta que é no meio do trabalho "que se desenrola boa parte da vida do trabalhador, cuja qualidade de vida está, por isso, em intima dependência com a qualidade de vida daquele ambiente".

Inobstante, é válido ressaltar que o meio ambiente do trabalho, como objeto primeiro do Direito Ambiental do trabalho foi tutelado pela carta Constitucional de 1988, de modo expresso, no artigo $7^{\circ}$, quando assegura entre os direitos dos trabalhadores urbanos e rurais, a "redução de riscos inerentes ao trabalho, por meio de normas de saúde, higiene e segurança" (item XXII), o adicional de remuneração para as atividades penosas, insalubres ou perigosas, na forma da lei" (item XXIII) e "seguro contra acidentes do trabalho, a cargo do empregador, sem excluir a indenização a que está obrigado, quando incorrer em dolo ou culpa" (item XXVIII).

Observa-se ainda que o meio ambiente (artigo 225) e o meio ambiente do trabalho em especial (artigo 200, VIII) receberam tutela constitucional específica no contexto da ordem social, que "tem como base o primado do trabalho, e como objetivo o bem-estar e a justiça sociais" (artigo 193 da Carta Constitucional de 1988).

Sapientes de que o Direito Ambiental do Trabalho possui como premissa a defesa de um meio ambiente de trabalho saudável, sustentável, equilibrado e seguro para os trabalhadores em geral, aí incluídos a categoria de trabalhadores autônomos, que não são regidos pela CLT, a exemplo do pescador artesanal. Tais trabalhadores também terão assegurado pelo Direito Ambiental do Trabalho o direito ao meio ambiente de trabalho saudável. 
Nessa esteira, se faz necessário entender a atividade da pesca artesanal para então compreender como o Direito Ambiental do Trabalho pode contribuir para a saúde e segurança do meio ambiente de trabalho desses trabalhadores, reduzindo os riscos a que estão sujeitos em razão do próprio meio ambiente de trabalho. Verificase que existe uma escassez, em verdade, uma lacuna na produção científica do Brasil que aborde diálogos entre a saúde, segurança e/ou sustentabilidade do meio ambiente de trabalho do pescador artesanal e o direito desse a um meio ambiente de trabalho saudável.

Dias Neto (2002, p. 164) nos ensina que a pesca possui 05 classificações, podendo ser divida: em pesca científica, pesca amadora, pesca de subsistência, pesca artesanal ou de pequena escala e pesca empresarial ou industrial. Interessanos aqui a pesca artesanal ou de pequena escala que é a realizada com objetivo exclusivamente comercial ou com dupla finalidade, comercial e de subsistência. Dias Neto e Dornelles (1996, p. 165) entendem que no Brasil a pesca artesanal se caracteriza por ser uma alternativa sazonal de trabalho, podendo o trabalhador atuar ora como agricultor, ora como pescador.

Para Dia Neto (2002, p. 164) a complexidade é uma das características inerentes à pesca artesanal, dada a diversidade de petrechos empregados na captura de pescados de estoques diversos, além da dispersão dos pontos de desembarque e da participação em diversas cadeias produtivas. Nesse contexto, a sabedoria tradicional e milenar sobre o mar e sobre a pesca são essenciais na arte de captura dos organismos e na exploração do ecossistema marinho. (Pena, 2011)

Outra característica da pesca artesanal é ser marcada pelo trabalho familiar, realizado por homens, mulheres, crianças e idosos em conjunto. Se caracteriza por ser uma profissão passada de geração a geração mediante o convívio familiar, através da tradição oral e da vivência da prática, com poucas modificações em relação ao método praticado durante milênios. (Moura; Santos Neto; Almeida, 2008)

Pena assim descreve o processo da produção da pesca artesanal no Brasil:

a pesca artesanal baseia-se em conhecimentos empíricos, adquiridos em família e transmitidos aos demais membros pelos mais velhos da comunidade. Resultando de uma atividade produtiva de caráter individual, com baixa divisão técnica, em que o artesão, em geral, é o proprietário dos seus instrumentos de trabalho, e sobrevive da venda do produto do seu trabalho. (...) O artesão controla a concepção e a execução do seu trabalho, detendo o "saber-fazer" (know-how) constituído de conhecimentos e domínio de métodos aplicados em todas as etapas do processo de produção. Há, portanto, uma unidade 
entre concepção e execução do trabalho, em que se observa a ausência de hierarquias gerenciais que separam o trabalho intelectual do manual. (Pena, 2011, p. 12)

Morin (1994) relata que a perda de espaço da produção artesanal no mundo está diretamente relacionada com a chegada da Revolução Industrial e a predominância globalizada do sistema Capitalista. Contudo, deve-se ressaltar que a prevalência do método industrial não eliminou a produção artesã, tanto que atividades artesãs como a pesca ainda são responsáveis pela subsistência de milhares de pessoas não só no Brasil como no mundo (SEAP, 2010).

Por certo, a Revolução Industrial acarretou mais do que o negligenciamento da produção artesã, ela foi a responsável, juntamente com fatores/circunstâncias, como a necessidade da intervenção estatal, o insurgimento da classe trabalhadora contra as condições de trabalho e o escasseamento e/ou poluição/degradação dos recursos naturais, pelo surgimento de marcos regulatórios na defesa dos trabalhadores que possuem vínculo empregatício e na proteção do meio ambiente natural. Levando-se a questionar porque para uma profissão tão antiga quanto à pesca artesanal, com o advento da Revolução Industrial, esta categoria também não contou com o surgimento de um arcabouço jurídico próprio na defesa de sua ocupação?

O que se percebeu é que a Revolução Industrial em todas as suas fases (primeira, segunda e terceira) sempre necessitou de matéria-prima, a qual era e permanece sendo extraída dos recursos da natureza e, da mão de obra, que eminentemente permanece a ser o homem, porém em menor proporção atualmente, haja vista o trabalho em grande quantidade que é realizado por máquinas. Assim, toda vez que a Revolução Industrial em suas diversas fases "exigiu demais", ocasionando a escravização da mão de obra humana e o desaparecimento da matéria prima ou a degradação da mesma, ergueram-se áreas do saber jurídico peculiares, a saber, o Direito do Trabalho e o Direito Ambiental na salvaguarda, respectivamente, do meio ambiente e do trabalhador vinculado a uma relação empregatícia.

Levantou-se hipótese no sentido de que a pesca artesanal, enquanto produção artesã, somente tenha vindo a sofrer regulamentação específica recente porque a pesca artesanal e o pescador artesanal permaneceram à margem do sistema capitalista globalizado, pelo fato de que ambos não eram necessários ao capitalismo como eram os recursos naturais e a mão de obra humana. Com o surgimento da 
Revolução Industrial a produção artesã é colocada de lado não só no mundo da produção, como no mundo jurídico no Brasil. É o que se percebe com a pesca artesanal, que contou com legislações específicas no Brasil com a edição hodierna das Leis Federais nํㅗ 11.958 e 11.959, as duas do ano de 2009, com exceção do Decreto-lei n. ํ 221/67, que fora revogado pela já citada Lei Federal nº 11.959/2009.

A Lei Federal no 11.958/2009 juntamente com a Lei Federal no 11.959/2009 são as principais normas federais do Brasil que tratam da pesca artesanal. A primeira transforma a Secretaria Especial de Aquicultura e Pesca em Ministério, estabelece as diretrizes sobre a matéria, prevendo a emissão de autorizações e permissões, bem como o Registro Geral da Pesca. Estabelece ainda as competências comuns do Ministério da Pesca e Aquicultura (MPA) e do Ministério do Meio Ambiente (MMA) com respeito ao uso sustentável dos recursos pesqueiros, além de manter o poder de polícia do Instituto Brasileiro do Meio Ambiente e dos Recursos Naturais Renováveis (IBAMA). Já a segunda é considerada o Código de Pesca vigente no Brasil, já que estabeleceu a Política Nacional de Desenvolvimento Sustentável da Aquicultura e da Pesca, em substituição ao Decreto-Lei Federal no 221/1967. A Política define conceitos e diretrizes que devem ser observados no ordenamento da gestão dos recursos pesqueiros (Brasil, 2009a, 2009b).

No âmbito federal há ainda decretos importantes que regulam a pesca artesanal, veja-se, pois:

O Decreto Federal no 1.694/1995 que institui o Sistema Nacional de Informações de Pesca e Aquicultura, atribuindo ao Instituto Brasileiro de Geografia e Estatística (IBGE) a competência para coordenar a implantação, o desenvolvimento e a manutenção do Sistema, contando com dados e informações produzidos por órgãos federais, estaduais, municipais, instituições de ensino e pesquisa e entidades envolvidas com o setor pesqueiro (Brasil, 1995).

O Decreto Federal no 5.069/2004 que cria o Conselho Nacional de Pesca (CONAPE) - órgão colegiado de caráter consultivo. Compete ao CONAPE subsidiar a formulação da política nacional para a pesca e aquicultura, propondo diretrizes para o desenvolvimento e o fomento da produção pesqueira e aquícola. Conta com a participação do Poder Executivo e sociedade civil organizada, como entidades e organizações dos movimentos sociais e dos trabalhadores da pesca (Brasil, 2004).

O Decreto Federal nº 6.981/2009 dispõe sobre a atuação conjunta do MMA e MPA com respeito ao uso sustentável dos recursos pesqueiros e cria a Comissão 
Técnica de Gestão Compartilhada (CTGP), órgão consultivo e coordenador das atividades do sistema de gestão compartilhada (Brasil, 2009c).

O que se observa é que todas essas legislações da esfera federal buscam alcançar a pesca artesanal no sentido da produção artesã, regulamentando-a, porém não normatizando os direitos dos trabalhadores da pesca artesanal, quiçá os direitos dos mesmos a um meio ambiente de trabalho saudável.

Para Pena (2011), o artesão autônomo deveria receber um tratamento privilegiado do sistema jurídico brasileiro haja vista que a saúde desse trabalhador encontra-se desassistida, devido à sua própria condição de autonomia no exercício do trabalho:

Não existe a possibilidade de uma instituição do Estado exigir do artesão a observância pelo empregador da prevenção dos riscos de acidentes e doenças do trabalho por meio de Normas Regulamentadoras, pois geralmente não há empregador, diferentemente do ocorre com o trabalhador assalariado. Para este, há relações formais com o empregador por meio de contrato regido pela Consolidação das Leis do Trabalho (CLT), onde se aplicam os regulamentos citados em situações que envolvem a contratos de trabalho. Nesse sentido, 0 artesão geralmente se encontra absolutamente sem assistência à saúde no trabalho e, por isso, deveria ser objeto da prioridade da ação do Estado nos programas de proteção à saúde do trabalhador no Sistema Único de Saúde. (Pena, 2011, p. 11)

O pescador artesanal na condição de trabalhador autônomo, o que ocorre em regra geral, não dispõe de norma jurídica específica que garanta os seus direitos a um meio ambiente de trabalho saudável e é por isso que ele se encontra desprotegido no que se refere ao exercício do seu trabalho e ao ambiente ao que o mesmo está exposto. Ora, trabalhadores regidos pela CLT dispõem de inúmeros dispositivos nessa, que buscam salvaguardar a vida, a saúde, a segurança e o equilíbrio do meio ambiente de seus trabalhadores. A CLT traz um conjunto de normas jurídicas, o que se verifica especialmente nos arts. 154 a 201 da mesma, objetivando disciplinar a saúde e segurança no trabalho.

Os arts. 154 a 201 compõem o capítulo da CLT que se refere a medicina e segurança no trabalho e está dividido em diversas seções, sendo elas: Seção I Disposições Gerais; Seção II - Da Inspeção Prévia e do Embargo ou Interdição; Seção III - Dos Órgãos de Segurança e de Medicina do Trabalho nas Empresas; Seção IV - Do Equipamento de Proteção Individual; Seção V - Das Medidas Preventivas de Medicina do Trabalho; Seção VI - Das Edificações; Seção VII - Da 
Iluminação; Seção VIII - Do Conforto Térmico; Seção IX - Das Instalações Elétricas; Seção X - Da Movimentação, Armazenagem e Manuseio de Materiais; Seção XI - Das Máquinas e Equipamentos; Seção XII - Das Caldeiras, Fornos e Recipientes sob Pressão; Seção XIII - Das Atividades Insalubres ou Perigosas; Seção XIV - Da Prevenção da Fadiga; Seção XV - Das Outras Medidas Especiais de Proteção; e Seção XVI - Das Penalidades. (Brasil, 1943)

Não somente os referidos artigos como as Normas Regulamentadoras editadas pelo Ministério do Trabalho legislam precipuamente acerca das normas de segurança e saúde no trabalho de trabalhadores regidos pela CLT, ou seja, aqueles que dispõem de vínculo empregatício, os quais estão sujeitos às relações de subordinação perante o empregador. De acordo com a CLT em seu art. 3ำ é empregado: "toda pessoa física que prestar serviços de natureza não eventual a empregador, sob a dependência deste e mediante salário". Inobstante, não são apenas celetistas que contam com um arcabouço jurídico protetivo da saúde e segurança dos trabalhadores nos ambiente de trabalho, os servidores públicos civis dispõem do art. 39, § 3ํ da CF/88, que estende a esses a consagração de normas do direito à redução de riscos inerentes ao trabalho, por meio de normas de saúde, higiene e segurança. (Brasil, 1943)

Observa-se que a pesca artesanal caracteriza-se por ser um regime produtivo extrativista de subsistência, com emprego de embarcações de pequeno e médio porte e equipamentos com pouca ou nenhuma sofisticação. Neste tipo de atividade laboral, o valor do trabalho é pago mediante a entrega do produto ou no serviço prestado. (Barbosa, 2004)

Os pescadores artesanais são identificados pela Classificação Brasileira de Ocupações (CBO) como pescadores polivalentes, contemplando os catadores de caranguejo e siri, catadores de mariscos, pescadores artesanais de lagostas e pescadores artesanais de peixes e camarões.

De acordo com a SEAP (2010) o pescador (a) artesanal é o profissional que, devidamente licenciado pelo Ministério da Pesca e Aquicultura, exerce a pesca com fins comerciais, de forma autônoma ou em regime de economia familiar, com meios de produção próprios ou mediante contrato de parcerias, desembarcada ou com embarcações de pequeno porte.

Dados da SEAP (2010) concluem que do total de cerca de 970 mil pescadores registrados, 957 mil são pescadoras artesanais, sendo que os mesmos estão 
organizados atualmente em cerca de 760 associações, 137 sindicatos e 47 cooperativas. Contudo, há aqueles que não estão registrados, informações extraoficiais sugerem que esse número pode chegar a mais de dois milhões de pessoas sobrevivendo da pesca artesanal no Brasil. Informações da SEAP (2010) relatam que são produzidos no Brasil 1 milhão e 240 mil de pescado por ano, sendo que cerca de $45 \%$ dessa produção é da pesca artesanal.

Por certo, os recursos pesqueiros constituem importante fonte de renda, geração de trabalho e da própria subsistência dos pescadores artesanais. Esses conhecem bem o ambiente no qual laboram, o mar, as marés, os manguezais, os rios, lagoas, os peixes, mariscos e crustáceos. Para a maior parte deles o conhecimento é passado de pai para filho ou pelas pessoas mais velhas e experientes de suas comunidades.

Pena (2011) relata que o trabalho acontece em equipe, sem supervisão. As atividades são realizadas a céu aberto, durante o dia. Segundo esse autor os pescadores artesanais, durante o desenvolvimento de sua atividade laboral, permanecem em posições desconfortáveis, expostos à variação climática e ferimentos inerentes à coleta dos pescados e mariscos. (Pena, 2011, p.12)

Pena (2011) ressalta que o fato do pescador artesanal não ser assalariado, regido pela CLT e laborar de forma autônoma trouxe para esse consequências jurídico-sociais:

Não dispor de salário resulta em profundas diferenças com outras categorias de trabalhadores assalariadas, inclusive relativos às suas relações com a prevenção de riscos ocupacionais. Como o pescador não recebe salários, não dispõe também de equipamentos de proteção individual, equipamentos de proteção coletiva, realização de exames médicos na admissão e nos periódicos, dentre outras obrigações legais dos empregadores para com seus assalariados. $O$ pescador artesanal é autônomo não apenas em relação à sua remuneração, mas quanto à proteção a sua saúde. Nesse sentido, o contrato que existe no trabalho do pescador se estabelece com a venda do produto ao consumidor ou atravessador. (Pena, 2011, p. 12)

A saúde do trabalhador da pesca artesanal encontra-se em risco "duplo", pois além desse estar exposto aos diversos riscos e a processos de adoecimento e até ao acometimento da perda da vida em decorrência do labor, esse ainda não possui a sua saúde no seu meio ambiente de trabalho jurídica-institucionalmente protegida, como ocorre com os trabalhadores celetistas no Brasil.

Apesar da nossa atual Carta Magna determinar de modo direto a redução dos riscos inerentes ao trabalho, como se verifica no art. $7^{\circ}$ : 
Art. 7 São diretos dos trabalhadores urbanos e rurais, além de outros que visem à melhoria de sua condição social:

$(\ldots)$

XXIII a redução dos riscos inerentes ao trabalho, por meio de normas de saúde, higiene e segurança.

O que se verifica na práxis é que a atividade da pesca artesanal está inserta de riscos dos mais diversos que não são estudados, não são sabidos pela comunidade científica. Essa falta de conhecimento acerca dos riscos a que está sujeito o trabalhador da pesca artesanal ocasionou uma lacuna no conhecimento. Assim, áreas do saber de suma relevância, como a epidemiologia, a vigilância sanitária, a higiene ocupacional, a ergonomia e outros campos do conhecimento que poderiam contribuir significativamente para a redução dos trabalhadores à exposição dos riscos estão ainda por avançar em relação a esta categoria. Afinal, somente pode-se promover a saúde desses trabalhadores, quando for possível se conhecer os riscos a que estão sujeitos em seu meio ambiente de trabalho.

No entanto, o trabalho deveria ser entendido e praticado em uma perspectiva de construção da saúde, de processos de enriquecimento biopsíquico, social, cultural e sob condições de sustentabilidade ecológica. O trabalho, central na vida humana, de acordo com Pena (2011, p. 13) pode sim gerar qualidade de vida e saúde, permitir a possibilidade de realização profissional e fortalecer a auto-estima do trabalhador.

Contudo, o trabalho também pode servir como fator determinante do acometimento de enfermidades e também da ocorrência de mortes. Não há dúvida, de que vários são os fatores que podem contribuir para o acontecimento de morbidades e mortalidades em decorrência do labor humano. Assim, também é sabido que o meio ambiente de trabalho é fato determinante na ocorrência desses.

Todavia, a falta de conhecimento sobre o meio ambiente de trabalho de determinadas profissões/categorias, especialmente nas categorias artesãs, como é o caso da atividade pesqueira torna-a ainda mais vulnerável aos mais variados riscos em seu meio ambiente de trabalho. Essa falta de conhecimento traz ainda uma invisibilidade generalizada, na qual o pescador artesanal, haja vista não estar protegido pela CLT, encontra-se despercebido do Estado brasileiro e, por conseguinte, das instituições responsáveis pelo cumprimento e fiscalização do cumprimento das normas de proteção da saúde do trabalhador.

Sapiente de que o pescador artesanal está sujeito a riscos como qualquer pessoa que exerce atividade laboral, faz-se imprescindível que novos estudos e 
pesquisas sejam desenvolvidas no sentido de permitir o diálogo, a transferência de conhecimentos e a geração de um novo conhecimento que possua como fundamento do Direito Ambiental do Trabalho protegendo, promovendo, desenvolvendo, gestando, planejando, executando e avaliando o meio ambiente de trabalho saudável do pescador artesanal.

Faz-se imperioso que não só a literatura discorra acerca do Direito Ambiental de Trabalho contribuindo positivamente para a regulamentação do meio ambiente de trabalho saudável, seguro, equilibrado e sustentável do pescador artesanal no Brasil, como, que sejam efetivadas políticas públicas no sentido de garantir a saúde e qualidade de vida desse trabalhador no meio ambiental do trabalho peculiar no qual se encontra inserido.

\section{Referências}

ANTUNES, Paulo de Bessa. Direito ambiental. Rio de Janeiro: Lumens Juris, 1996.

ARAGÃO, José Augusto Negreiros. Análise da consistência estatística do Programa de Coleta de Dados de Desembarque de Pescado, executado pelo IBAMA, no nordeste do Brasil. Dissertação (mestrado). Ceará, Universidade Federal do Ceará, Departamento de Engenharia de Pesca, 1997.

BARBOSA, Sônia Regina da Cal Seixas. Identidade social e dores da alma em pescadores artesanais em Itaipu, RJ. Ambiente \& Sociedade, 7(1):107-131, 2004.

BEZERRA, Benedito Paulo. A saúde mental no nordeste da Amazônia: estudo de pescadores artesanais. 2002. 89 f. Tese (Doutorado). São Paulo: Universidade Federal de São Paulo, Escola Paulista de Medicina, 2002.

BRASIL. Constituição da República Federativa do Brasil de 1988. São Paulo: Saraiva, 2013.

Decreto-Lei $n^{\circ} 5.452$, de $1^{\circ}$ de maio de 1943. Consolidação das Leis do Trabalho. Brasíli: São Paulo: Saraiva, 2013.

Lei $n^{0} 11.958$, de 26 de junho de 2009. Altera as Leis $n^{0 s} 7.853$, de 24 de outubro de 1989, e 10.683, de 28 de maio de 2003; dispõe sobre a transformação da Secretaria Especial de Aquicultura e Pesca da Presidência da República em Ministério da Pesca e Aquicultura; cria cargos em comissão do Grupo-Direção e Assessoramento Superiores - DAS e Gratificações de Representação da Presidência da República; e dá outras providências. Brasília: Ministério da Pesca e Aquicultura, 2009.

Lei $n^{\circ}$ 11.959, de 26 de junho de 2009. Dispõe sobre a Política Nacional de Desenvolvimento Sustentável da Aquicultura e da Pesca, regula as atividades pesqueiras, revoga a Lei no 7.679, de 23 de novembro de 1988, e dispositivos do Decreto-Lei no 221, de 28 de fevereiro de 1967, e dá outras providências. Brasília: Ministério da Pesca e Aquicultura, 2009. 
. Decreto $n^{\circ}$ 5069, de 5 de maio de 2004. Dispõe sobre a composição, estruturação, competências e funcionamento do Conselho Nacional de Aqüicultura e Pesca - CONAPE, e dá outras providências. Brasília: Ministério da Pesca e Aquicultura, 2004.

Decreto $n^{\circ} 6981$, de 13 de outubro de 2009. Regulamenta o art. 27, §6o, inciso I, da Lei no 10.683 , de 2003, dispondo sobre a atuação conjunta dos Ministérios da Pesca e Aquicultura e do Meio Ambiente nos aspectos relacionados ao uso sustentável dos recursos pesqueiros. Brasília: Ministério da Pesca e Aquicultura e Ministério do Meio Ambiente, 2009.

Ministério da Saúde. Doenças Relacionadas ao Trabalho: Manual de procedimentos. Brasília: Ministério da Saúde, 2001.

Ministério do Trabalho e Emprego. Norma Regulamentadora n. 15, Atividades e Operações Insalubres. Brasília: Ministério do Trabalho e Emprego, 2012 [on line] Disponível em: http://www.mte.gov.br/legislacao/normas regulamentadoras/nr 09 at.pdf. Acesso em: 23 de fevereiro de 2013.

. Ministério da Saúde. Portaria no. 1.679, de 19 de setembro de 2002. Aprova a constituição da Rede Nacional de Atenção à Saúde do Trabalhador (RENAST). Brasília: Ministério da Saúde, 2002.

. Ministério do Trabalho e Emprego, Ministério da Previdência e Assistência Social \& Ministério da Saúde. Portaria Interministerial no. 800, de 3 de maio de 2005. Aprova a Política Nacional de Segurança e Saúde do Trabalhador. Brasília: Ministério do Trabalho e Emprego, Ministério da Previdência e Assistência Social \& Ministério da Saúde, 2005.

. Ministério da Saúde. Portaria no . 3.027, de 2007. Aprova a Política Nacional de Gestão Estratégica e Participativa no PARTICIPASUS. Brasília: Ministério da Saúde, 2007.

- Ministério da Pesca e Agricultura. Plano Safra de Pesca e Aquicultura. Brasília: Ministério da Pesca e Agricultura, 2012. [on line] Disponível em: http://www.presidencia.gov.br/estrutura presidencia/seap/. Acesso em: 23 de fevereiro de 2013.

. Ministério de Pesca e Agricultura. Estatística de Aquicultura e Pesca no Brasil - ano 2005 . [on line] Disponível em: http://200.198.202.145/seap/Dados estatisticos/boletim2005a(tabela).pdf. Acesso em: 12 de janeiro de 2013.

\begin{tabular}{ccccc} 
& Ministério de Pesca e Aquicultura. O Diagnóstico da Pesca Extrativa no \\
\hline Brasil & ano $2005 . \quad$ [on line] Disponível
\end{tabular} http://200.198.202.145/seap/html/diagnostico.htm. Acesso em: 12 de janeiro de 2013.

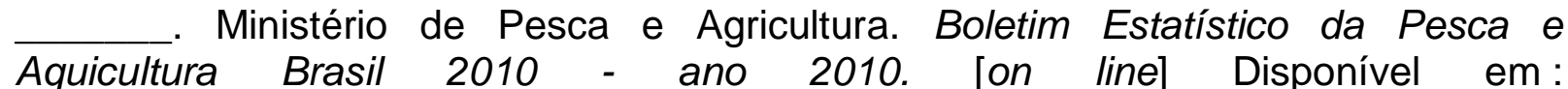
http://www.mpa.gov.br/images/Docs/Informacoes e Estatisticas/Boletim\%20Estat\%C 3\%ADstico\%20MPA\%202010.pdf. Acesso em: 12 de janeiro de 2013.

Ministério do Trabalho e Emprego. Classificação Brasileira de Ocupações. Brasília: Ministério do Trabalho e Emprego, 2012 [on line] Disponível em: 
http://www.mtecbo.gov.br/cbosite/pages/pesquisas/BuscaPorTituloResultado.jsf. Acesso em: 23 de fevereiro de 2013. . Ministério do Meio Ambiente. Estatística da Pesca de 2004. Brasília: Ministério do Meio Ambiente, 2005.

BRASIL, Silvio. O desafio da atuação interinstitucional e intersetorial na saúde e segurança de pescadores artesanais do estado do Pará. Gestão Pública: Revista do Sistema de Formação e Aperfeiçoamento da Escola de Governo do Estado do Pará, 1(1): 23-27, 2007.

BRAVERMAN, Harry. Trabalho e o capital monopolista: a degradação do trabalho no Século XX. 3를. São Paulo: Zahar, 1980.

CAMPOS, José Gaspar Ferraz. Agenda 21: da Rio 92 ao local de trabalho. São Paulo: Iglu, 1996.

DALL'OCA, Adiar Vagner. Aspectos sócio-econômicos, de trabalho e de saúde de pescadores do Mato Grasso do Sul. Dissertação (mestrado). Mato Grosso do Sul, Universidade Federal de Mato Grosso do Sul, 2004.

DEJOURS, Christophe e DESSORS, Dominique e DESRIAUX, François. Por um trabalho, fator de equilíbrio. Revista de Administração de Empresas. São Paulo, 33(3):98-104, 1993.

DERANI, Cristiane. Direito ambiental econômico. São Paulo: Max Limonad, 1997.

DIAS, Elizabeth Costa. A atenção à saúde dos trabalhadores no setor saúde (SUS) no Brasil: realidade, fantasia ou utopia. Tese (doutorado). São Paulo, Unicamp, Faculdade de Ciências Médicas, 1994.

DIAS NETO, José. Gestão do uso de recursos pesqueiros marinhos no Brasil. Dissertação (mestrado). Brasília, Universidade de Brasília, 2002.

DORNELLES, Lia Drumond. Diagnóstico da pesca marítima do Brasil. Brasília: Ibama, 1996.

FERNANDES, Annibal. Os acidentes do trabalho: do sacrifício do trabalho à prevenção e à reparação: evolução legislativa, atualidade e perspectivas. São Paulo: LTr, 1995.

FIGUEIREDO, Guilherme José Purvin de. Direito ambiental e a saúde dos trabalhadores. São Paulo: LTr, 2000.

- Direito ambiental e a saúde dos trabalhadores: controle da poluição, proteção do meio ambiente, da vida e da saúde dos trabalhadores no Direito Internacional na União Européia e no MERCOSUL. São Paulo: LTr, 2007.

FIORILLO, Celso Antônio Pacheco. Princípios do direito processual ambiental: a defesa judicial do patrimônio genético, do meio ambiente cultural, do meio ambiente artificial, do meio ambiente do trabalho e do meio ambiente natural no Brasil. 4. ed. São Paulo: Saraiva, 2010.

FIORILLO, Celso Antonio Pacheco e RODRIGUES, Marcelo Abelha. Manual de Direito Ambiental e Legislação Aplicável. 2ª ed. São Paulo: Max Limonad, 1999.

FREIRE, Paulo. Pedagogia do oprimido. Rio de Janeiro: Paz e Terra, 1987.

FREITAS, Maria do Carmo Soares de. Agonia da fome. Salvador, Rio de Janeiro: Edufba; FIOCRUZ, 2003. 
GARRONE NETO, Domingos e CORDEIRO, Ricardo Carlos e HADDAD JR., Vidal. Acidentes do trabalho em pescadores artesanais da região do Médio Araguaia, Tocantins, Brasil. Cadernos de Saúde Pública, Rio de Janeiro, 21(3):795-803, 2005.

GEERTZ, Clifford. Interpretação das culturas. Rio de Janeiro: Guanabara, 1989.

GRANZIERA, Maria Luiza Machado. Direito de águas e meio ambiente. São Paulo: Ícone, 1993.

HAGUETTE, Teresa Maria Frota. Metodologias qualitativas na sociologia. Petrópolis: Vozes, 1987.

HORVATH JÚNIOR, Miguel. Direito previdenciário. São Paulo: Quartier Latin, 2005.

LACAZ, Franciso Antônio de Castro. Cenário e estratégias em saúde dos trabalhadores de 1986 a 1994. Em: II Conferência Nacional de Saúde dos Trabalhadores. Brasília: Ministério da Saúde, 1994.

LÉVI- STRAUSS, Claude. O olhar distanciado. Lisboa: Edições 70, 1986.

MACIEL, José Fabio Rodrigues e AGUIAR, Renan. História do Direito. São Paulo: Saraiva, 2007.

MANCUSO, Rodolfo de Camargo. Ação civil pública. 12. ed. São Paulo: Ed. Revista dos Tribunais, 2011. v. 1. 200 p.

MARX, Karl. O capital. Livro 1, Capítulo VI. São Paulo: Ciências Humanas, 1978.

MELO, Raimundo Simão de. Direito ambiental do trabalho e a saúde do trabalhador: responsabilidades legais, dano material, dano moral, dano estético, indenização pela perda de uma chance, prescrição. 4. ed. São Paulo: LTr, 2010.

MENDES, Rene. (Org.). Patologia do Trabalho, vol. 1. São Paulo: Atheneu, 2005.

MINAYO, Maria Cecília de Souza. Pesquisa social: teoria, método e criatividade. Rio de Janeiro: Vozes, 1994.

MORIN, Edgar. Sociologie. Paris: Librairie Arthème Fayard, 1994.

MOURA, Diogo Fernando Gramacho de; SANTOS NETO, Aristotelino Osvaldo dos e ALMEIDA, Rosiléia Oliveira de. A etnoecologia das marisqueiras da comunidade de Praia Grande, Ilha de Maré, Salvador-BA. Candombá - Revista Virtual, Bahia, 4(2): 91-110, 2008.

NUSDEO, Fábio. Ecologia e desenvolvimento. São Paulo: Saraiva, 1975.

PADILHA, Norma Sueli. Do meio ambiente do trabalho equilibrado. São Paulo: LTr, 2002.

PAULA, Paulo Mazzante de. Trabalho informal e exclusão social: perspectivas para a efetivação do Estado Democrático de Direito. Bauru: Canal 6, 2012.

PENA, Paulo Gilvane Lopes. Programa de prevenção de riscos ocupacionais em pescadores e marisqueiras de comunidades pesqueiras da Baia de Todos os Santos. Formulário-Síntese da Proposta - SIGProj. Salvador: Edital Proext, 2011. Relatório do Programa Proext, 2011.

PINTO, Almir Pazzianotto. Direito ambiental do trabalho. Revista Cej, Brasília,1(3):511, 1997. 
RAMAZZINI Bernadino. As doenças dos trabalhadores. São Paulo: FUNDACENTRO, 1985.

ROBORTELLA, Luiz Carlos Amorim. Direito do trabalho e meio ambiente. In: SILVESTRE, Rita Maria e NASCIMENTO, Amauri Mascaro (coord). Os novos paradigmas do direito do trabalho: homenagem a Valentin Carrion. São Paulo: Saraiva, 2001.

ROCHA, Julio Cesar de Sá da. A proteção legal ao meio ambiente no estado da Bahia e outros estudos de direito sanitário. Feira de Santana: UEFS, 1996.

ROCHA, Julio Cesar de Sá da. Direito ambiental e meio ambiente do trabalho: dano, prevenção e proteção jurídica. São Paulo: LTr, 1997.

ROCHA, Julio Cesar de Sá da. Direito Ambiental do Trabalho. São Paulo: LTr, 2002.

SADY, João José. Direito do meio ambiente de trabalho. São Paulo: LTr, 2000.

SANTOS, Adelson Silva dos. Fundamentos do direito ambiental do trabalho. São Paulo: LTr, 2010.

SANTOS, Milton. Por uma outra globalização: do pensamento único à consciência universal. São Paulo: Record, 2000.

SCHERER, Elenise. Mosaico Terra-Água: a vulnerabilidade social ribeirinha na Amazônia - Brasil. Em: VIII Congresso Luso-Afro-Brasileiro de Ciências Sociais. Coimbra, 2004. [on line] Disponível em: http://pepsic.bvspsi.org.br/scielo.php?script=sci arttext\&pid=S003496902008000100001\&Ing=pt\&nrm =is.

SCHWARTZ, Germano. O tratamento jurídico do risco no direito à saúde. Porto Alegre: Livraria do Advogado, 2004.

SEILLAN, Hubert. Obligations et responsabilities em droit du travail et em droit de l' environnement. Droit et Ville: Revue de l' Institut des Études Juridiques de I' Urbanisne et de la construction (Paris), 37: páginas 48-64, 1994.

SERRANO, José Luis. Formación y autonomia del derecho ambiental. In: VARELLA, Marcelo Dias e BORGES, Roxana Cardoso Brasileiro (Orgs). O novo em direito ambiental. Belo Horizonte: Del Rey, 1998.

SILVA, José Afonso da. Direito constitucional positivo. 15 ed., São Paulo: Malheiros, 1998.

SILVA, José Afonso da. Direito ambiental constitucional. 3. ed. São Paulo: Malheiros, 2000.

SILVA, José Afonso da. Direito ambiental constitucional. 5. ed. São Paulo: Malheiros, 2004.

SOARES, Evanna. Ação ambiental trabalhista: uma proposta de defesa judicial do direito humano ao meio ambiente do trabalho no Brasil. Porto Alegre: Sérgio Antonio Fabris, 2004.

TRINDADE, Antônio Augusto Caçando. Direito à saúde como ao direito a um meio ambiente sadio. In: TRINDADE, Antônio Augusto. Caçando Direitos humanos e meio ambiente: paralelo dos sistemas de proteção internacional. Porto Alegre: Fabris, 1993. 
Anais dos III Congresso Iberoamericano de Direito Sanitário / || Congresso Brasileiro de Direito Sanitário

TOMANIK, Eduardo Augusto e BERCINI, Luciana Olga. Representações Sociais de Saúde entre as mulheres de pescadores profissionais do município de Porto Rico Paraná. In: Caderno de Resumos da II Jornada Internacional sobre Representações Sociais - Questões Metodológicas, Florianópolis, 1:176-177, 2001. Disponível em: http://www.peld.uem.br/Relat2001/pdf/componente socioecon saude.PDF. 